\title{
Laser ablation of upper gastrointestinal vascular ectasias: long term results
}

\author{
I R Sargeant, L A Loizou, D Rampton, M Tulloch, S G Bown
}

\begin{abstract}
Forty one patients with bleeding vascular ectasias of the upper gastrointestinal tract who required blood transfusion were treated with endoscopic Nd:YAG laser photocoagulation and followed for 34 months (median). Four distinct groups of patients were identified. There was a sustained reduction in transfusion requirements after laser treatment in all those with single (nine patients) and multiple (seven patients) angiodysplasia, in 12 of $16(75 \%)$ patients with watermelon stomachs, and in six of nine $(66 \%)$ patients with hereditary haemorrhagic telangiectasia. Overall, 25 patients $(61 \%)$ required minimal or no transfusion after treatment and nine (22\%) whose bleeding was controlled initially, later developed recurrent bleeding which was controlled with further laser (total 34 of $41,83 \%$ ). Surgery succeeded in a further three patients (7\%) in whom laser had failed (in one case possibly because of laser induced haemorrhage). Five more cases of possible laser induced haemorrhage resolved with conservative treatment. One patient sustained a treatment related perforation and died: one patient with cirrhosis died of encephalopathy within one month of starting laser treatment. In two patients transfusion requirements were unchanged despite laser. Nd:YAG laser is a safe and effective treatment for most patients with upper gastrointestinal angiodysplasia.
\end{abstract}

(Gut 1993; 34: 470-475)

Vascular ectasias of the upper gastrointestinal tract are a relatively rare cause of recurrent and sometimes severe blood loss. They are increasingly being diagnosed in patients with lesions that may have been regarded as unimportant in the past. This is, at least partly a result of the proliferation of new devices and techniques that are being used to ablate, sclerose, or embolise the lesions. Success has been reported with several endoscopic treatments. These include monopolar and bipolar electrocoagulation, ${ }^{1-4}$ heater probe, ${ }^{45}$ injection sclerotherapy, ${ }^{6}$ and at first argon and then Nd:YAG laser ablation. ${ }^{4-11}$ Although there are few data on open surgery for upper gastrointestinal vascular lesions there is little doubt that these newer, less invasive methods represent an important advance. Results of surgery for colonic vascular lesions show a high morbidity, significant mortality, and a recurrence of at least $10 \% .{ }^{12}{ }^{13}$ Experience with endoscopic techniques is mainly short term, although there is now some long term follow up of patients treated endoscopically for upper gastrointestinal lesions. ${ }^{14161920}$ This study aimed to add to the long term follow up data on $\mathrm{Nd}$ :YAG laser treatment of these patients and to define the patient groups in whom laser was most likely to be successful.

\section{Methods}

\section{PATIENTS}

Forty eight patients were seen at University College Hospital with acute or chronic blood loss from upper gastrointestinal tract vascular malformations over a nine year period to November 1990; of these, 43 were referred from other centres. Seven were excluded from the analysis (see below). Five of the remaining 41 had previously been treated with argon laser and four had had surgery; all nine continued to bleed. Demographic patient data are shown in Table I. The median patient age was 73 (range 24-90) years and 16 of $41(39 \%)$ were male. Sixteen (39\%) patients had associated disorders (excluding those with hereditary haemorrhagic telangiectasia, the most common being valvular heart disease. Twenty two patients (54\%) pre-

TABLE I Demographic patient data for each of the subgroups and all patients

National Medical Laser Centre, University College Hospital, London I R Sargeant, L A Loizou, D Rampton, M Tulloch, S G Bown

Correspondence to: Dr I R Sargeant, National Medical Laser Centre, Rm 103, The Rayne Institute, $\mathrm{Rm}$
5 University Street, London WCIE 6JJ.

Accepted for publication 7 September 1992

\begin{tabular}{|c|c|c|c|c|c|c|c|}
\hline Patient group & $\begin{array}{l}\text { Age }(y)(\text { median } \\
(\text { range) })\end{array}$ & No & $M / F$ & Associations & $\begin{array}{l}\text { Presentation } \\
\text { with } \\
\text { anaemia } \\
\text { only }\end{array}$ & $\begin{array}{l}\text { Presentation } \\
\text { with } \\
\text { acute bleed } \\
\text { only }\end{array}$ & $\begin{array}{l}\text { Presentation } \\
\text { with acute } \\
\text { bleed and } \\
\text { longstanding } \\
\text { anaemia }\end{array}$ \\
\hline Single angiodysplasia & $59(21-88)$ & 9 & $5 / 4$ & $\begin{array}{l}1 \text { Blood dyscrasia }{ }^{\star} \\
2 \text { Valvular heart disease } \\
2 \text { Chronic renal failure }\end{array}$ & 4 & 4 & 1 \\
\hline $\begin{array}{l}\text { Multiple angiodysplasia } \\
\text { Hereditary haemorrhagic } \\
\text { telangectasia }\end{array}$ & $\begin{array}{l}76(67-85) \\
66(55-81)\end{array}$ & $\begin{array}{l}7 \\
9\end{array}$ & $\begin{array}{l}3 / 4 \\
6 / 3\end{array}$ & $\begin{array}{l}1 \text { Von Willebrand's disease } \\
1 \text { Valvular heart disease } \\
1 \text { Blood dyscrasia }\end{array}$ & $\begin{array}{l}3 \\
3\end{array}$ & $\begin{array}{l}2 \\
1\end{array}$ & $\begin{array}{l}2 \\
5\end{array}$ \\
\hline Watermelon stomach & $72(51-86)$ & 16 & $3 / 13$ & $\begin{array}{l}2 \text { Valvular heart disease } \\
3 \text { Cryptogenic cirrhosis } \\
1 \text { Alcoholic cirrhosis } \\
1 \text { CRST syndrome } \\
1 \text { Chronic renal failure }\end{array}$ & 12 & 2 & 2 \\
\hline All patients & $71(21-88)$ & 41 & $17 / 24$ & As above & 22 & 9 & 10 \\
\hline
\end{tabular}

* One patient had valvular heart disease and a blood dyscrasia. CRST=Calcinosis, renaulds, sclerodactaly, and telangiectasis. 
sented with chronic iron deficiency anaemia and $19(46 \%)$ presented with acute upper gastrointestinal bleeding. Ten of the latter group also had chronic iron deficiency anaemia.

All patients underwent a diagnostic upper gastrointestinal tract endoscopy before treatment (usually at the same session). A positive diagnosis was based on the identification of one or more bright red mucosal lesions or the appearance of watermelon stomach. The lesions encountered in the former group varied in size from $1 \mathrm{~mm}-1 \mathrm{~cm}$ and usually had clearly defined margins. Those in the latter group were often multiple, and sometimes confluent, affecting varying proportions of the antrum. A frequent finding was linear streaks of ectasia radiating proximally from the pylorus, where the lesion always stopped abruptly.

Analysis of the pattern of lesions as discussed allowed patients to be put into one of four groups. Patients with typical mucocutaneous lesions and a positive family history were considered to have hereditary haemorrhagic telangiectasia. All other patients had either single or multiple angiodysplasias and were allocated to the appropriate groups. The fourth group comprised patients with watermelon stomachs. Two patients treated early on in this series were subsequently allocated to this group after the condition was fully described. ${ }^{17}$

Most patients with watermelon stomach and hereditary haemorrhagic telangiectasia presented with chronic iron deficiency anaemia, often of several years duration, although the diagnosis was sometimes made only after an acute bleed. In contrast, patients with single and multiple angiodysplasias presented in equal numbers with anaemia and acute bleeding. The group with hereditary haemorrhagic telangiectasia usually had more than 10 lesions and these occurred throughout the upper gastrointestinal tract with no particular pattern. Those with multiple lesions but not hereditary haemorrhagic telangiectasia had up to 10 lesions but two

TABLE II Long term outcome of all 41 patients with bleeding upper gastrointestinal tract angiodysplasia

\begin{tabular}{lcllc}
\hline & $\begin{array}{l}\text { Minimal/no } \\
\text { transfusion } \\
\text { requirement } \\
\text { after laser } \\
(\text { No(\%)) }\end{array}$ & $\begin{array}{l}\text { Transfusion } \\
\text { requirement } \\
\text { controlled } \\
\text { with laser } \\
(\text { No(\%)) }\end{array}$ & $\begin{array}{l}\text { Laserfailure } \\
(\text { No(\%)) }\end{array}$ & $\begin{array}{l}\text { Transfusion } \\
\text { requirement } \\
\text { controlled or } \\
\text { abolished } \\
\text { (laser+surgery) }\end{array}$ \\
\hline Single angio & $8 / 9(89 \%)$ & $1 / 9(11)$ & $0(0)$ & $9 / 9(100)$ \\
Multiple angio & $4 / 7(57)$ & $3 / 7(43)$ & $0(0)$ & $7 / 7(100)$ \\
Watermelon stomach & $9 / 16(56)$ & $3 / 16(19)$ & $4 / 16(25)$ & $13 / 16(81)$ \\
Hereditary haemorrhagic telangiecta & $4 / 9(44)$ & $2 / 9(22)$ & $3 / 9(33)$ & $8 / 9(88)$ \\
Total & $25 / 41(61)$ & $9 / 41(22)$ & $7 / 41(17)$ & $37 / 41(90)$ \\
\hline
\end{tabular}

TABLE III Transfusion requirements according to lesion type during long term follow up

\begin{tabular}{|c|c|c|c|}
\hline $\begin{array}{l}\text { Lesion type } \\
\text { (no of patients) }\end{array}$ & $\begin{array}{l}\text { Transfused blood } \\
1 \text { y before laser } \\
\text { treatment (units) }\end{array}$ & $\begin{array}{l}\text { Follow up } \\
\text { (mth) }\end{array}$ & $\begin{array}{l}\text { Transfused blood } \\
\text { (units/y) } \\
\text { during follow up }\end{array}$ \\
\hline \multicolumn{4}{|c|}{ Hereditary haemorrhagic telangiectasia (7) } \\
\hline $\begin{array}{l}\text { Meadian (range) } \\
\text { mean }\end{array}$ & $\begin{array}{l}8(4-42) \\
14 \cdot 0\end{array}$ & $\begin{array}{l}51(12-118) \\
75\end{array}$ & $\begin{array}{l}4(0-44) \\
6\end{array}$ \\
\hline \multicolumn{4}{|c|}{ Multiple angiodysplasia (7) } \\
\hline$\underset{\text { mean }}{\text { Median (range) }}$ & $\begin{array}{l}10(4-23) \\
12 \cdot 3\end{array}$ & $\begin{array}{l}60(16-82) \\
46\end{array}$ & $\begin{array}{l}2(0-10) \\
4 \cdot 3\end{array}$ \\
\hline \multicolumn{4}{|c|}{ Single angiodysplasia (9) } \\
\hline Median (range) & $17(2-95)$ & $38(6-75)$ & $0(0-14)$ \\
\hline $\begin{array}{l}\text { mean } \\
\text { Watermelon stoma }\end{array}$ & & 35 & $1 \cdot 6$ \\
\hline $\begin{array}{l}\text { Median (range) } \\
\text { mean }\end{array}$ & $\begin{array}{l}8(2-26) \\
9 \cdot 5\end{array}$ & $\begin{array}{l}27(6-60) \\
19\end{array}$ & $\begin{array}{l}4(0-25) \\
3 \cdot 0\end{array}$ \\
\hline
\end{tabular}

to three was a more typical pattern. They were usually located along the lesser curve or in the second part of the duodenum; a similar distribution to that in patients with single angiodysplasias.

\section{EXCLUSIONS}

The following groups of patients were excluded:

(i) Patients in whom no transfusions were required (two patients) (as transfusion requirements were used to assess results).

(ii) Patients who refused further treatment before adequate coagulation was achieved (two patients).

(iii) Follow up of less than six months available (two patients).

(iv) Patients with other pathology (one patient). This patient had been extensively investigated at another hospital and found to have several small stomach angiodysplasias. Despite a good laser result further transfusions were required. Repeat colonoscopy showed a small caecal cancer which was graded Dukes's A on histology. It was resected and the patient remains well, with no blood loss, a year later.

\section{TECHNIQUES}

The endoscopic and laser techniques have been published in detail elsewhere. ${ }^{14}{ }^{15} 17$ It is particularly important that care is taken with suction to avoid endoscope trauma that can be mistaken for vascular lesions. Gastric secretions and blood are cleared away by gentle washing. The power setting is adjusted as necessary to ensure that the mucosal surface is blanched when treated in $0.5 \mathrm{~s}$ pulses (usually $50 \mathrm{~W}$ ). The aim is to coagulate tissue down to the submucosa, where most of the abnormal vessels are situated; the mucosal lesion represent only the tip of the iceberg. ${ }^{14}$ Lesions that bled spontaneously and those which oozed on gentle washing were considered most likely to be important sites of blood loss and were treated first. Treatment was started at the lesion edge in order to coagulate abnormal feeding vessels in adjacent submucosa.

Most patients with hereditary haemorrhagic telangiectasia and multiple angiodysplasias and all those with watermelon stomachs required repeated sessions to coagulate all visible lesions in contrast to those with single angiodysplasias where one or two sessions was usually adequate. All patients were given at least a four week course of $\mathrm{H}_{2}$ receptor antagonists after laser in order to assist induced ulcer healing.

\section{FOLLOW UP}

After diagnosis a pragmatic approach was taken toward further investigation. Colonscopy was initially deemed unnecessary in patients who presented with haematemesis and in those with lesions seen to be bleeding actively or which showed stigmata of recent bleeding. All patients who continued to have clinically important bleeding underwent further investigation. Overall, 13 patients underwent colonscopy: small lesions were detected in four but these were thought to be clinically unimportant. All 
patients were given iron supplements and blood transfusions as required to maintain an adequate haemoglobin concentration. At initial referral, the blood transfusion requirements were documented from the date of the first transfusion and subsequently on a prospective basis. These data were used to assess the efficacy of treatment. Long term follow up was carried out six monthly at the referring hospitals and by our research sister (DM or MT). All patients were seen again at this hospital when further bleeding occurred. One treatment was given at each admission, and a period of four to six weeks between treatments allowed induced ulcers to heal. The duration of follow up for each group is given in Table III. Patients with single angiodysplasias required a median of two procedures, which were carried out in the first year of treatment (mostly in the first three month period). Those with multiple angiodysplasias required a median of three procedures in the first two years of treatment. In contrast, patients with hereditary haemorrhagic telangiectasia and watermelon stomachs required a median of six treatments over two years, and they continued to require further regular treatments after this period. Patients who presented with further bleeding had lesions in the same distribution as that noted at previous endoscopies.

All but one patient were followed up to the second half of 1990 . Eleven patients died during follow up. Two died shortly after the initia treatment (see results), three died from cardiac causes, one from pneumonia, one with septicaemia, and one with carcinomatosis. The exact cause of death in the other three patients is not known but was not the result of bleeding and was thought to be related to 'old age'.

One patient with hereditary haemorrhagic telangiectasia developed a small villous adenoma in the fundus seven years after the start of laser treatment. This area had been treated previously

\section{all patients bleeding in} corresponding three month periods before and after laser treatment.
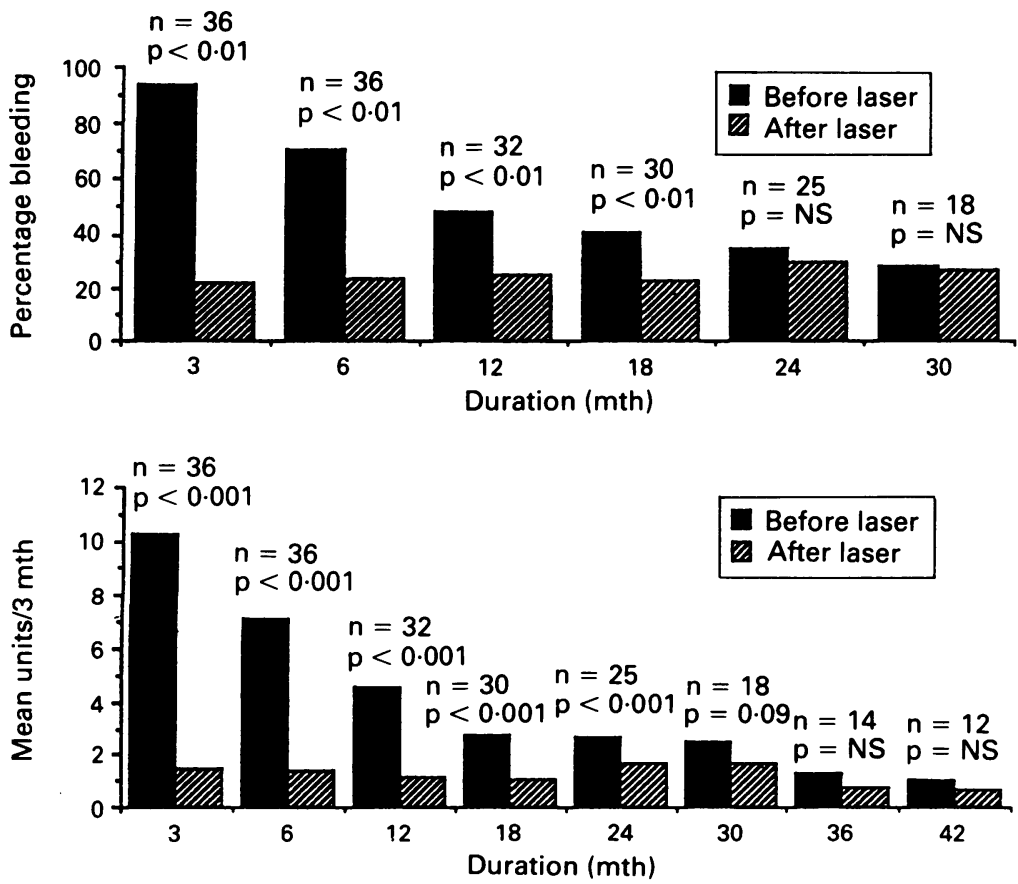

Figure 2: Mean transfusion requirements per three month period before and after laser are shown for all patients treated with laser. Significance ( $p)$ has been calculated using the Wilcoxon signed rank test for paired data and $n=$ number of patients followed for the relevant time. with laser but so had many other areas in the stomach and duodenum. The adenoma has been treated with laser and has not recurred after 18 months.

\section{STATISTICAL METHODS}

Statistical analyses were performed using the sign test (binomial equation) and Wilcoxon signed rank test for paired data.

\section{Results}

Bar charts of blood transfusion in relation to time were drawn for all patients and the timing of laser treatments was marked. On the basis of these charts patients were put into one of the following three categories:

(a) Minimal or no transfusion requirement (transfusion of less than 2 units per year).

(b) Transfusion requirement controlled (a substantial and sustained reduction in transfusion requirement which could be comfortably satisfied without recourse to other measures.

(c) Laser failure.

The results by lesion type are presented in Table II. Twenty five patients $(61 \%)$ fulfilled the criteria for group 1. A further nine (22\%) benefited from control of their transfusion requirement (group 2). Thus 34 of $41(83 \%)$ of all patients benefitted from laser alone.

\section{BLEEDING RATE AND TRANSFUSION \\ REQUIREMENTS}

The percentage of patients who bled in each three month period for the given duration is shown in Figure 1. Three patients who underwent surgery and two who died within one month of the start of treatment have been excluded, leaving 36 patients in the analysis. The number of bleeding episodes for a given period before and after the start of treatment were compared so that the period before treatment could be used as a control. There was a dramatic reduction in the numbers of patients who bled after treatment, and this is significant at the $1 \%$ level up to 18 months (sign test, binomial equation).

Mean transfusion requirements by three month period before and after laser treatment are shown in Figure 2. These data are presented as above. As the follow up periods increase, the difference between requirements before and after narrow, and statistical difference is lost after two years (Wilcoxon signed rank).

Table III gives transfusion data for each lesion category. Patients with single angiodysplasias bled more before treatment and showed the most dramatic fall in transfusion requirements (significant to 24 months). Each of the other groups showed significant reduction in transfusion requirements up to 18 months (Wilcoxon signed rank).

\section{LASER FAILURES AND COMPLICATIONS}

Continued bleeding controlled with surgery

Three patients underwent surgery for bleeding 
and all have required only the occasional blood transfusion over a follow up period of 40 to 69 months. One had a watermelon stomach and two had hereditary haemorrhagic telangiectasia. All three patients bled heavily before laser treatment (18-26 units transfused in three months) and all continued to bleed heavily afterwards and required surgery. Two of these patients required a total gastrectomy but the other (the one with hereditary haemorrhagic telangiectasia) had antral lesions oversewn. The first of these patients may have had a laser induced haemorrhage $^{141523}$; this was seen in four further patients after the initial treatment and in another patient after further laser 21 months after treatment had started. All but one of these patients had been bleeding profusely before laser treatment, however, and it is difficult to be certain whether laser treated areas caused this bleeding or if untreated lesions were responsible.

Continued bleeding not controlled (three patients) Two patients continued to bleed at a similar rate after repeated laser treatment but their transfusion requirements were met without recourse to surgery. One with a watermelon stomach continued to require blood transfusion at the rate of 1-2 units per month. The second had multiple stomach lesions and hereditary haemorrhagic telangiectasia and continued to need around 4 units per month. A third patient with unchecked bleeding was a 72 year old lady with a watermelon stomach who had bled 72 units in 24 months before referral. She had end stage cryptogenic cirrhosis and CRST syndrome and died one month after starting laser treatment (four sessions) of hepatic encephalopathy.

\section{Perforation (one patient)}

One perforation occurred in a 72 year old man with a watermelon stomach and cryptogenic cirrhosis. He had been referred from a distant hospital with heavy upper gastrointestinal bleeding and was treated with a large amount of laser energy $(14000 \mathrm{~J})$, which in hindsight was excessive. He developed a perforation seven days after treatment, a decision was taken not to treat him further in view of his generally poor condition, and he died.

\section{Antral narrowing (two patients)}

Two cases of asymptomatic antral narrowing were noted at follow up endoscopy in patients with watermelon stomachs.

\section{Discussion}

Long term control of bleeding was achieved in $\mathbf{9 0 \%}$ of patients referred for laser treatment of upper gastrointestinal angiodysplasia. Patients with single angiodysplasia did particularly well despite the fact that they presented with greater transfusion requirements. We gained excellent control in eight of nine patients and reasonable control in the ninth. All patients with multiple angiodysplasia benefited from laser. The results for those with watermelon stomachs and heredi- tary haemorrhagic telangiectasia are not quite as good but most patients also show a considerable reduction in the transfusion requirement. The main drawback of this type of treatment for the latter two groups is the need for repeat endoscopy throughout the follow up period. This is because of the natural history of the disease, which leads to the development of further lesions in a similar distribution to the original ones. Although we did not routinely rescope all patients to check on the endoscopic results of treatment, many patients (particularly those with watermelon stomachs) were treated several times to cover the entire lesion. At each session treated lesions had usually regressed and we feel confident that late rebleeding was caused by growth of new lesions or by extension of the original lesions beyond their previous limits.

It is possible that we have slightly overestimated the blood transfusion requirement related to gastrointestinal bleeding as there were several patients who continued to require transfusions who had other possible causes of anaemia. Three patients with hereditary haemorrhagic telangiectasia had recurrent nose bleeds, although only one of these required more than 2 units of blood per year of follow up. Neither of the two patients with blood dyscrasias required more than 2 units per year of follow up but one patient with Von Willebrand's disease and multiple angiodysplasia continued to require modest transfusions after treatment, although the requirement was dramatically reduced. Three patients had chronic renal failure but only one with a single angiodysplasia continued to require blood and that at a much reduced rate. Four patients were seen with cirrhosis, although only one (with a watermelon stomach) had varices, and these had been well sclerosed three years before presentation. She did not rebleed after start of treatment.

It could be argued that thresholds for transfusion in general have been raised in the past few years because of greater awareness of complications of transfusion such as HIV infection and hepatitis. We, in common with most UK physicians, have always been conservative with transfusions, and these are only given when patients suffer severe bleeding or have noticeable symptoms of anaemia. We do not, however, think any significant change in the transfusion threshold has occurred in this group of patients over the study period.

How do these results compare with other published data? Rutgeerts et al in $1985^{15}$ followed 25 patients with bleeding from upper gastrointestinal angiodysplasia and 34 with colonic angiodysplasia for a mean period of one year after Nd:YAG laser treatment. Four of the patients with upper gastrointestinal lesions required surgery. Objective comparison is difficult as the results for upper and lower gastrointestinal lesions are combined. There was a noticeable reduction in bleeding, however, but not complete haemostasis in all patients. Results for patients with hereditary haemorrhagic telangiectasia and those with Von Willibrand's disease were poor and it is of interest that patients with 'diffuse capillary haemangiomas' (presumably watermelon stomachs) were con- 
sidered to be too extensive to treat. Another recent study with $\mathrm{Nd}$ :YAG laser also showed patients with hereditary haemorrhagic telangiectasia to be more difficult to control long term. ${ }^{16}$ Thirteen patients with hereditary haemorrhagic telangiectasia showed a reduction in the transfusion requirement in the second and third years after start of treatment but this was not statistically significant. Of 47 patients with bleeding angiodysplasias, only 15 rebled during a median follow up of 19 months.

There are three recent reports ${ }^{162021}$ suggesting abolition of blood loss in patients with watermelon stomachs treated with thermal methods. The first of these documents 12 patients treated with heater probe. Two of these patients had never required transfusion. The remaining 10 were transfused a median of 9 units before treatment. There was a prompt reduction in blood loss but two patients required one further transfusion after start of treatment. Follow up was for a median of 18 months only. The second ${ }^{20}$ used Nd:YAG laser and similar results were obtained. Twelve patients were treated eight of whom had required transfusions (median 5.5 units) beforehand. None needed transfusion after treatment but transfusion data were not available on one patient who required surgery. Follow up was for a median of 5.5 months only. The third report documents only one patient in whom blood loss was arrested for 11 months after Nd:YAG laser treatment. ${ }^{21}$

These results look better than ours but this may be explained by patient selection and short follow up; almost all our patients came as tertiary referrals, often with a long history of anaemia and a total transfusion requirement greater than that in other published series. The median total blood loss before treatment in our patients was 11 units and the median duration of symptoms was three years. Our follow up is longer (33 months median) and in our experience the incidence of rebleeding increases with time. It could be argued that patients with this lesion would be better treated with antrectomy, which is curative. This group, however, are elderly and have a high incidence of concurrent medical conditions which substantially increases the risk of surgery. Indeed the two treatment failures who died in this group had advanced liver disease and were not deemed fit for surgery in any circumstances. We feel that endoscopic treatment should be attempted first in these patients but would not rule out surgery for difficult cases.

Delayed haemorrhage is now a well established complication of laser treatment. It was first documented in $1982^{22}$ and has been seen by us and other groups. ${ }^{14}$ is $\mathrm{Six}$ patients bled after laser and one of them required surgery, although all of these were bleeding heavily before treatment. It is therefore difficult to determine if the laser was really responsible and they would have certainly come to surgery without endoscopic treatment. Laser induced bleeding has been shown to originate from the edge of the induced ulceration $^{22}$ and we have speculated that it may be caused by an edge of a laser induced necrotic zone occurring within an area of vascular ectasia. ${ }^{14}$ Since 1985 , we have treated around the lesion before coagulation at the centre, thus destroying feeding vessels, and we have seen only two possible cases of delayed haemorrhage since.

In contrast to delayed haemorrhage, acute bleeding after Nd:YAG laser coagulation of these lesions is common, usually self limiting, and is often taken as a clinically important sign. It is, however, important not to continue treating these lesions as further laser shots may vaporise the angioma and induce more bleeding.

One patient suffered a perforation. In retrospect, this patient was treated with an excessive amount of energy even though the lesion was very extensive. Experimental studies have shown that the maximum safe dose at one point is around $300 \mathrm{~J}^{23} 24$ and we think this was exceeded. Certainly we have been treating patients with extensive lesions with higher energies in recent years and patients treated more recently have required fewer treatment sessions. When such a case occurs, however, we must go back to the original experimental data to remind ourselves of the safe parameters.

With increasing awareness, angiodysplasia is often picked up at routine endoscopy and the clinical relevance of these lesions may not be immediately clear. If the patient concerned has not bled and is not anaemic then treatment of these lesions should certainly not be undertaken. If, however, there is a clinical bleeding problem and the lesion is seen to be bleeding at endoscopy it is reasonable to go ahead and treat. The follow up of these patients is important and we recommend a low threshold for colonoscopy. The patient in whom a caecal cancer was picked up shows the importance of such an approach.

Other modes of endoscopic treatment such as argon laser, monopolar probes, bipolar electrocoagulation, and probably injection sclerotherapy can give results similar to those attained with laser and it is likely that, as with treatment of bleeding peptic ulcers, the best results are obtained with the technique which is most familiar to the endoscopist concerned. On the basis of experimental studies we would argue that the Nd:YAG laser which penetrates down to the submucosal vascular lakes causing tissue coagulation without vaporisation is a more logical tool than the argon laser. Some groups, however, ${ }^{24}{ }^{25}$ have reported excellent results with argon laser and a recent review ${ }^{26}$ suggests a higher incidence of complications (in particular perforation) with the $\mathrm{Nd}$ :YAG laser. These have occurred mainly in the lower gastrointestinal tract where the bowel wall is thinner, and particular care is required with the Nd:YAG laser. An advantage of laser over the other (contact) techniques is that trauma induced bleeding and adhesion of the probe is avoided. Monopolar probes cause deeply penetrating lesions and are thus theoretically more likely to induce perforation, although some groups report good results with minimal complications. ${ }^{27} 28$ Bipolar electrocoagulation causes superficial damage rather like the argon laser but good results have also been reported. ${ }^{+}$There are fewer data for injection sclerotherapy but good results have been reported for patients with hereditary haemorrhagic telangiectasia. ${ }^{6}$ A recent study used an oestrogen-progesterone preparation in 
10 patients with frequent and severe bleeding from gastrointestinal vascular lesions. ${ }^{29}$ Bleeding stopped in eight while on treatment and one showed a dramatic fall in transfusion requirements. Such an approach may be useful in patients who do not respond to endoscopic methods, although the risk of complications such as cardiovascular events is not yet clear.

On the basis of these results we feel that $\mathrm{Nd}$ :YAG laser treatment is a relatively safe and effective technique for treating bleeding from upper gastrointestinal vascular lesions. There is a definite perforation risk with this laser, but if patients are treated with caution this is minimised. Long term results are convincing. Many patients still require some blood transfusions, although at a much reduced rate. We find the $\mathrm{Nd}$ :YAG laser easier to use than the other endoscopic techniques, particularly with extensive lesions, and on the basis of the results reported here we feel that it is justified to refer these patients for this treatment.

All authors were supported by the Department of Health Specia Medical Development on Lasers.

1 Weingart J, Elster K, Ottenjann R. Recurrent gastrointestinal bleeding in Osler's disease successfully treated by endoscopic electrocoagulation in the stomach. Endoscopy 1975; 7: scopic elec 4 .

2 Weaver GA, Alpern HD, Davis JS, Ramsey WH, Reichelderfer $M$. Gastrointestinal angiodysplasia associated with aortic valve disease: part of a spectrum of angiodysplasia of the gut. Gastroenterology 1979; 77: 1-11.

3 Howard OM, Bucanan JD, Hunt RM, Mc Carter. Angiodysplasia of the colon. Lancet 1982; ii: 16-19.

4 Jensen DM, Machicado GA, Silpa ML. Treatment of GI angiomata with argon laser, heater probe or bipolar electrocoagulation. Gastrointest Endosc 1984; 30: 134.

5 Petrini JL, Johnson JH. Heat probe treatment for antral vascular ectasia. Gastrointest Endosc 1989; 35: 324-8.

6 Young W, Gilbert V, Feinstat T, Trudeau W. The recurrent upper gastrointestinal bleeding in hereditary haemorrhagic telangectasia (Osler's disease) successfully treated by endotelangectasia (Osler's disease) successfully treated by
scopic sclerotherapy. Gastrointest Endosc 1982; 28: 148 .

7 Bowers JH, Dixon JA. Argon laser photocoagulation of vascular malformations of the GI tract: short terms results. Gastrointest Endosc 1982; 28: 126

8 Waitman AM, Grant DZ, Chateau F. Argon laser photocoagulation treatment of patients with acute and chronic bleeding secondary to telangectasia. Gastrointest Endosc 1982; 28: 153 .
9 Cello JP, Grendell JH. Endoscopic laser treatment for gastrointestinal vascular ectasias. Ann Intern Med 1986; 104: $352-4$

10 Gostout CJ, Ahlquist DA, Radford CM, Viggiano TR, Bowyer $\mathrm{BA}$, Balm RK. Endoscopic laser therapy for watermelon stomach. Gastroenterology 1989; 96: 1462-5.

11 Tsai HH, Smith J, Danesh BJ. Successful control of bleeding from gastric antral vascular ectasia (watermelon stomach) by laser photocoagulation. Gut 1991; 32: 93-4.

12 Richardson JD, Max MH, Flint LM. Bleeding vascular malformations of the intestine. Surgery 1978; 84: 430-4.

13 Boley SJ, Sammartano R, Brandt LJ, Sprayregen S. Vascular ectasias of the colon. Surg Gynacol Obst 1979; 149: 353-9.

14 Bown SG, Swain CP, Storey DW, Collins C, Matthewson K, Salmon PR et al. Endoscopic laser treatment of vascular Salmon PR et al. Endoscopic laser treatment of vascular
anomalies of the upper gastrointestinal tract. Gut 1985; 26: anomalies

15 Rutgeerts P, Van Gompel F, Geboes K, Vantrappen G, Broeckaert $L$, Coremans $G$. Long term results of treatment of vascular malformations of the gastrointestinal tract by Neodymium YAG laser photocoagulation. Gut 1985; 26: 586-93.

16 Naveau S, Aubert A, Poynard T, Chaput JC. Long-term results of treatment of vascular malformations of the gastrointestinal tract by neodymium YAG laser photocoagulation. Dig Dis Sci 1990; 35: 821-6.

17 Jabbari M, Cherry R, Lough JO, Daly DS, Kinnear DG, Goresky CA. Gastric antral vascular ectasia: the watermelon Goresky CA. Gastric antral vascular ectasia:

18 Loizou LA, Bown SG. Clinical laser applications in the gastrointestinal tract. In: Pounder RE, ed. Recent advances in gastrointestinal, vol 7. London: Churchill Livingstone, 1988: 47-87.

19 Petrini JL, Johnsston JH. Heat Probe treatment for antra vascular ectasia. Gastrointest Endosc 1989; 35(4): 324-8.

20 Tsai HH, Smith J, Danesh BJ. Successful control of bleeding from gastric antral vascular ectasia (watermelon stomach) by laser photocoagulation. Gut 1991; 32: 93-4.

21 Johnson JH. Complications following endoscopic laser therapy. Gastrointest Endosc 1982; 28: 126.

22 Bown SG, Salmon PR. Nd:YAG laser photocoagulation in the dog stomach. Gut 1980; 21: 818-25.

23 Rutgeerts P, Vantrappen G, Geboes K, Broeckaert L. Safety and efficacy of Neodymium YAG laser photocoagulation; an experimental study in dogs. Gut 1981; 22: 38-44.

24 Brunetard JM, Maunoury V, Cochelard D, Cortot A, Paris $\mathrm{JD}$. Laser treatment for vascular malformations of the digestive tract. In: Jensen DM, Bruntaud JM, eds. Medical laser endoscopy. Kluwer Academic Publisher, 1990: 93-8.

25 Waitman AM, Graut DZ, Chateau F. Argon laser photocoagulation treatment of patients with acute and chronic bleeding secondary to telangiectasia. Gastrointest Endosc 1982; 30: 134.

26 Rutgeerts P, Vantrappen G. Non-acute bleeding: angiodysplasia and other vascular anomalies. In: Krasner N, ed. Lasers in gastroenterology. London: Chapman and Hall Lasers in gastroenterolo
Medical 1991. 109-23.

27 Rogers BHG. Endoscopic diagnosis and therapy of muscosal vascular abnormalities of the gastrointestinal tract occuring in elderly patients and associated with cardiac, vascular and in elderly patients and associated with cardiac, vascular
pulmonary disease. Gastrointest Endosc 1980; 26: 134-8.

pulmonary disease. Gastrointest Endosc 1980; 26: 134-8.
28 Howard OM, Buchanan JD, Hunt RM. Angiodysplasia of the colon. Lancet 1982; ii: 16-19.

29 Van Cutsem E, Rutgeerts P, Vantrappen G. Treatment of bleeding gastrointestinal vascular malformations with oestrogen-progesterone. Lancet 1992; 335: 953-5. 